\title{
Que povo é esse?
}

\section{Résumé}

Cet article examine la représentation de l'autre à travers la forme lexicale povo [peuple] dans le discours présidentiel de la République Militaire Brésilienne (1964-1984). Cette forme de représentation s'est avérée un instrument politique très efficace car, par son biais, ont été construites deux fonctions énonciatives distinctes - le porte-parole et le médiateur - qui font travailler l'ambiguité qui caractérise ce discours. Ces deux fonctionnements discursifs montrent que, sous l'apparence du consensus - effet tissé par la fonction du porte-parole - le silence est instauré dans cet espace discursif à travers la fontion du médiateur - simulacre de porte-parole. Le jeu énonciatif établi par la superposition de ces deux fonctions dévoile l'imaginaire du sujet de ce discours. 


\title{
QUE POVOÉ ESSE?
}

\author{
Todo poder emana do povo \\ e em seu nome será exercido \\ Figueiredo
}

\section{PRIMEIRAS PALAVRAS}

reflexão proposta neste artigo inicia-se em trabalhos anteriores
construção discursiva da referência de povo no discurso presidencial militar
brasileiro e o segundo, com base no primeiro, examina fundamentalmente
o efeito de metáfora de povo brasileiro, construído no mesmo discurso.

No presente trabalho, volto ao item lexical povo para examinar o modo como o sujeito desse discurso, ao representar o outro, assume funções enunciativas específicas - de porta-voz e de mediador.

É preciso salientar que, através dessas funções, povo é apenas mencionado, produzindo-se, por conseguinte, um discurso sobre o povo $\mathrm{em}$ substituição ao discurso do povo, o qual reflete fortemente as formações imaginárias que presidem o discurso em pauta.

Por fim, faz-se necessário explicitar que esse trabalho inscreve-se no marco teórico da Análise do discurso.

\section{POVO, SUAS REPRESENTAÇÕES E SUAS PROPRIEDADES}

Inicialmente, devo salientar que povo como entidade global não existe, registrando-se no discurso em análise uma grande amplitude referencial que será objeto de descrição na grade que segue. 


\begin{tabular}{ll} 
NÍVEL & DESCRIÇÃO DO REFERENTE \\
\hline POVO1 & $\begin{array}{l}\text { classe média, classes produtoras, } \\
\text { militares, refolucionários - os que } \\
\text { apoiam a revolução }\end{array}$ \\
\hline POVO2 & classes trabalhadoras \\
\hline POVO 3 & coletividade dos brasileiros \\
\hline POVO 4 & sociedade civil organizada \\
\hline POVO 5 & massa de manobra política \\
\hline
\end{tabular}

Como é possível observar, com exceção de POVO 3, que é um coletivo, os demais níveis referenciais constituem empregos partitivos desse item lexical. Os três primeiros níveis fazem-se presentes nos cinco domínios discursivos que constituem o espaço em análise, enquanto os dois últimos só foram registrados no domínio discursivo do presidente Figueiredo.

Os diferentes níveis referenciais foram estabelecidos através do efeito de sentido que povo promove nesse espaço discursivo. Explicitando melhor, os sentidos descritos não precedem o discurso, nem seus efeitos de sentido derivam de outro, mas constroem-se pelo trabalho do discurso propriamente dito, no âmbito de seu processo discursivo que está inscrito em uma formação discursiva.

Para os propósitos do presente artigo, fiz um recorte, fixando-me apenas nos dois primeiro níveis, representados na grade referencial precedente.

\section{POVO 1 - aqueles que apóiam a Revolução}

No discurso sobre o povo, sua configuração em primeiro nível remete a uma parcela específica da classe média, que apoiou o movimento de 31 de março, como o recorte ${ }^{1}$ que segue evidencia.

CB1 - (...) Na verdade, o povo brasileiro, ao se lavantar em armas, procurou restabelecer a autodeterminação e o ambiente das liberdades fundamentais que vinham sendo massacradas pelos comunistas em todas as partes do Governo brasileiro. $O$ povo brasileiro, ao agir como agiu, procurou (... ) contribuir para a paz universal, arrancando do cenário 
da administração brasileira o comunismo divisionista e derrotista. (CB1 - 8.05.64 - Dia da Vitória - Ex-Combatentes, p. 102)

CS1 - Ordem e progresso não são ( . . . ) palavras vãs ( . . ) são palavras sagradas, expressando a firme determinação de um povo que abomina a anarquia, a desordem, a violência, a escravidão política ou a opressão social, que despreza a ditadura e os ditadores e, por isso mesmo, sabe impor sua vontade apoiando este Governo, que é o "seu" Governo, é o Governo do povo, é o Governo que trabalha para o povo e que vive, sobrevive e se fortalece no povo. (CS1 - 3.10.68 - ARENA, SP, p. 426)

M1 - Está bem viva na memória do país a marcha da família pelas ruas, do sentimento religioso e cristãode nosso povo, exigindo o fim de todos os desmandos. ( $\mathrm{M}-31.3 .70-6^{\circ}$. Aniv. da Revolução, TV, p. 87)

G1 - O povo, através de suas mais autênticas expressões - a igreja de Cristo, a imprensa responsável, autênticas lideranças políticas, associações de classe $(. .$.$) e de cultura - e as Forças Armadas$ que são povo também - irmanaram-se (...) Os militares (...) souberam aguardar ( . . m) manifestações inconfundíveis da vontade popular. (G1 - 31.3.74 - TV - 10. Aniv. Revolução, p. 63)

F1 - ( . . Coube às Forças Armadas nacionais a missão histórica de deter o curso da política mais contrária às aspirações do nosso povo jamais instalada entre nós. A família brasileira reagia com resolução e ânimo à iminente destruição das nossas instituições políticas tradicionais. ( F1 - 31.3 .80 - Palácio do Planalto $-16^{\circ}$. Aniversário Revolução, p. 39)

Através de POVO 1 o discurso presidencial constrói um povo que referencia aqueles que se opuseram às diretrizes do Governo anterior, organizando-se no sentido de derrubá-lo. Assim, em CB1, por exemplo, o item lexical povo remete aos militares, enquanto $\mathrm{G} 1$ refere diferentes segmentos da sociedade que estavam descontentes. Leia-se aí, entre outros, classes produtoras, latifundiários, partidos de direita. Ou seja, segmentos da sociedade que discordavam dos rumos tomados pelo Governo Goulart. Finalmente, em M1, encontramos mais uma especificação para POVO 1. Lembra-se aí a mobilização das mulheres paulistas de classe média que ficou conhecida como a "marcha da família com Deus pela liberdade". Enfim, todos os segmentos de direita que protestaram em nome da Nação são tomados, nesse recorte discursivo, como povo, ou seja, como aqueles que apoiaram e deram origem à Revolução de 31 de março. 
O apoio obtido no passado é projetado discursivamente sobre os governos "revolucionários"sucessivos, como indica CS1. De modo que o Regime Militar retirou de POVO1 a legitimidade necessária para sua instauração bem como para os atos que se lhe seguiram. Em outras palavras, os protestos que precederam o golpe assumem as características de um discurso fundador (ORLANDI, 1993:24), que funciona como uma procuração oficial passada pelo povo, mas de um discurso desse sujeito que se constrói como o intérprete dos anseios de POVO 1. Esse sujeito faz-se povo em POVO 1 e, ao falar, dá-lhe voz, constituindo-se em seu porta-voz autorizado. Essa é a função enunciativa que o sujeito do discurso presidencial assume ao representar o outro como POVO 1.

Por outro lado, o uso de povo joga com o sentido historicamente cristalizado que esse termo adquiriu a partir da Revolução Francesa, produzindo a grande ilusão discursiva cujo efeito é o de universalização desse partitivo, de tal forma que fala em nome dos simpatizantes da Revolução, mas parece falar em nome de todos, fazendo parecer comunitárias preocupações de fato específicas. Em torno dessa ilusão, abusos são cometidos em nome do povo que se institui discursivamente como a base de sustentação do Regime Militar.

Esse é o trabalho de prestidigitação discursiva que POVO 1 produz nesse espaço discursivo. É o que se pode inferir através de CS1: "um governo do povo que trabalha para o povo e se fortalece no povo".

Tomar a palavra em nome de POVO 1 como se este fosse um coletivo reveste o discurso de autoridade, porque fala-se em nome de POVO 1, simulando falar em nome de todos. Isto constrói o efeito de sentido de unanimidade (INDURSKY, 1995).

\section{POVO 2 - classes trabalhadoras}

No discurso sobre o povo, sua configuração em segundo nível o representa como aquela parcela da população que trabalha, que constrói o Brasil de amanhã, mas que não o usufrui. Isto é o que veremos no recorte que segue.

CB2 - Só uma lição podemos aprender do comportamento realista das classes trabalhadoras brasileiras: é que a elas, como povo, não interessam as soluções de catástrofe, não as seduzem a destruição e o aniquilamento da ordem e dos valores democráticos. (CB3 - 28.2.66 - BH - Assembléia Legislativa Estadual - Título Cidadão Mineiro, p. 5) 
CS2 - ( . . ) foi um ano tranquilo, um ano de entendimento, um ano de compreensão, não só entre os órgãos do Governo, como também do povo brasileiro, porque continuamos exigindo sacrifícios a esse povo, que já luta com dificuldades várias. (CS1 - 30.11 .67 - Pal. Planalto - Saudação de Improviso Deputados e Senadores - Término Ano Legislativo, p. 275)

M2 - Venho acenar ao povo trabalhador a solidariedade que um homem simples no Governo ao povo pode dar ( . . E) Este homem não pode acenar ao povo o dinheiro que não pode dar. Este homem não pode acenar ao povo a promessa fácil que não pode resgatar. $\mathrm{E}$ este homem não pode, e não deve, e não quer acenar a imagem fantasiosa de esperança vã, da mentira doce, da ilusão inebriante $(\ldots)\left(\mathrm{M}-25.1 .70-416^{\circ}\right.$. Aniversário da Fundação de São Paulo, p. 20)

G2 - ( . . ) No Dia Universal do Trabalho - quando ( . . ) exaltase realmente, em comunhão nacional, o espírito de todo o povo desta terra que, com o suor de suas mãos e a energia de suas vontades (... ), constrói o Brasil grande de amanhã. (G1 - 1.5.74 - TV, p. 83)

F2 - Uma democracia que sabe que o mal do nosso povo é a falta de instrução. Uma democracia que saiba que o que falta ao nosso povo é trabalho. É poder aquisitivo para se alimentar (...) Infelizmente, para nós, temos que reconhecer que o nosso povo tem mais ansiedade de saciar sua fome e de ter um teto, do que saber se os partidos vão se organizar desta ou daquela maneira. (F1 - 18.09.79 - Brasília - Improviso Maluf e bancada SP, p. 153)

O segundo nível referencial de povo recorta uma camada bem diversa daquela referenciada no nível anterior. Aqui não há protestos contra o governo anterior, não há manifestações contra o comunismo, nem marchas da "família brasileira". Através de POVO 2 é construída a imagem de povo trabalhador, generoso, comprensivo e sofredor e sempre pronto ao sacrifício.

No que tange ao discurso em análise, não se trata evidentemente do discurso do povo, mas de um discurso construído pelo sujeito do discurso sobre o povo e a ele atribuído. Mas, neste nível, não há procuração passada para esse fim, tal como ocorre em POVO 1. O discurso produzido em nome de POVO2 não institui o sujeito do discurso como seu porta-voz. O sujeito desse discurso, não se fazendo povo nesse segundo nível, porque a ele não pertence, dele afasta-se. Sua voz, por conseguinte, não está autorizada a falar em nome do POVO 2. Este apropria-se da voz do povo, 
assumindo a posição de seu mediador. Essa é a função enunciativa que o sujeito do discurso presidencial assume ao representar o outro como POVO2.

Enquanto o sujeito desse discurso é o porta-voz legítimo de POVO 1, emprestando-lhe a voz, o mesmo não ocorre com POVO 2, cuja voz é silenciada e substituída por um simulacro da voz do povo. Dito em outras palavras: o sujeito do discurso em análise, fazendo-se povo em POVO 1, ao falar, faz ouvir a voz autorizada do segmento a que pertence. $\mathrm{O}$ mesmo não ocorre com POVO 2. Conseqüentemente, POVO 2 permanece sem voz e o discurso que lhe é atribuído pertence, de fato, ao sujeito do discurso que se instituiu como seu mediador. Ao outorgar-se tal direito, atua como um ventríloquo, já que seu não-pertencimento ao segmento não autentica seu discurso.

Desse modo, POVO 2 é um simulacro e somente enquanto constructo é possível concebê-lo como povo que aceita espontaneamente sofrer e, por ser "sábio e justo", não acredita na "insensibilidade"atribuída ao Governo. Trata-se de um povo construído discursivamente, segundo a imagem que melhor convém ao sujeito desse espaço discursivo.

Assim, a distinção que, num primeiro momento, opunha, através de diferentes níveis referenciais, efeitos de sentido diversos - POVO 1 e POVO 2 - conduz, numa segunda instância analítica, a distinguir aqueles que são detentores de uma vontade veiculada por seu porta-voz, daqueles cujos direitos e necessidades são silenciados e substituídos por um simulacro que veicula, de fato, um discurso que representa os interesses do mediador.

Veja-se um pouco mais de análise para examinar o funcionamento desse nível referencial. Classes trabalhadoras, nesse contexto, produzem um duplo efeito de sentido complementar: por um lado, são aqueles que dependem de salário e, por outro, são aqueles que foram convocados para construir o Brasil de amanhã. É bem verdade que as questões salariais não são igualmente abordadas nos cinco domínios deste discurso. Encontramse explicitadas apenas nos três últimos. E Médici, ao mencioná-las, o faz com muita felicidade, afirmando que "a economia pode ir bem, mas a maioria do povo ainda vai mal". Essa sequência discursiva remete para a conjuntura econômica dos anos 70, quando se fazia "o bolo crescer" para só depois dividi-lo.

Sabe-se que o bolo cresceu, originando o assim chamado "milagre econômico", mas seus beneficiários certamente não se encontram entre 
aqueles que POVO 2 referencia, haja vista que, em seu discurso, Geisel refere-se ao massacre do povo "através dos salários". O mesmo ocorre em Figueiredo, que aponta a necessidade de "melhorar as condições de vida do povo brasileiro"que "sofre as agruras da inflação". Ou seja, o discurso dos três últimos presidentes, de algum modo, refere os problemas de POV02. No entanto, nenhum deles lhe atribui sentimentos hostis. Esse constructo representa um povo sempre disponível, como podemos ler em Figueiredo: "nosso povo não está desgostoso. O nosso povo apenas anseia por uma melhora de vida". Esta é a visão que o mediador constrói sobre POVO 2.

Em suma, o sujeito desse discurso em sua função enunciativa de mediador de POVO 2 constrói-se como o detentor do saber - aquele que sabe como o povo é - "comportamento realista das classes trabalhadoras" (CB); dotado de "vocação para a grandeza" (CS); provido de "incansável e provada tenacidade; . . . não se sente por parte do povo um agressivo mal-estar e sim uma paciência que ainda não se esgotou ... " (G). Nesse sentido, sabe igualmente o que o povo precisa - "o remédio ao alcance da bolsa"(M); "o mal do nosso povo é a falta de instrução . . . o que falta ao nosso povo é trabalho ... é poder aquisitivo para se alimentar". (F). Bem como sabe o que o povo não quer - "não lhe interessam as soluções de catástrofe, não o seduzem a destruição e o aniquilamento da ordem e dos valores democráticos" (CB). Em contraponto, constrói o povo como aquele que nada sabe, pois não pode acenar-lhe a "imagem fantasiosa de esperança vã, da mentira doce, da ilusão inebriante" (M); "nosso povo tem mais ansiedade de saciar sua fome e de ter um teto, do que saber se os partidos vão se organizar desta ou daquela maneira" (F); "não tememos o voto do povo; este é que deve ter medo de se enganar pois sempre que isso ocorre cabe-lhe pagar um tributo doloroso e irrecuperável" (CB). Ou seja, politicamente o povo, que nada sabe, é protegido pelo mediador que proverá suas necessidades por ser "dotado de um excedente de visão". (ZOPPI-FONTANA, 1994). A ignorância de POVO 2 também afeta sua competência lingüística, privando-o de acompanhar o debate sobre a conjuntura nacional: "venho para falar ao povo a linguagem que o povo entende, a linguagem de homens na praça" $(M)$.

Ou seja, o sujeito desse discurso é um sujeito que se supõe saber que fala como mediador em nome de POVO 2 que nada sabe e pode ser facilmente "mistificado" (G) pelos "despotistas e exploradores da miséria do povo" (F). Assim, no afã de proteger POVO 2, essa proteção bem depressa adquire um efeito de sentido pejorativo e o sujeito do discurso transforma-se em seu tutor - "o que me move é, tão só, a aspiração de 
procurar e encontrar na alma do povo ressonância para tudo aquilo que, em sua intenção e benefício, almejo realizar" (CS).

Esse discurso do mediador, produzido em substituição à voz do povo, dá origem a uma relação assimétrica que Osakabe (1979) chama de relação de jominação, marcada pela falta de reversibilidade, traço que Orlandi (1983) erige como característico do discurso autoritário.

Pode-se estabelecer uma comparação entre as propriedades desse discurso e as do discurso religioso, tomando por base o relacionamento entre o sujeito do discurso e o outro, em sua configuração como POVO 2. Penso que esse funcionamento assemelha-se à relação assimétrica descrita por Orlandi (1983, pp. 214 - 237) em seu estudo sobre o discurso religioso, pois há uma grande diferença entre o estatuto jurídico do sujeito do discurso presidencial em análise e o de POVO 2: o sujeito do discurso decide em nome de POVO 2, projetando seu sacrifício presente em troca de um futuro glorioso.

O paralelismo entre o discurso religioso e o discurso político acima mencionado prende-se exatamente a esse último aspecto e pode ser expresso da seguinte forma: assim como o homem adquire com seu sofrimento na terra a promessa de ingresso no paraíso, da mesma forma, POVO 2, por ser forte face ao sacrifício que lhe é exigido hoje, será recompensado com um futuro brilhante: "peço que o povo volte seu pensamento comigo, para bem longe, ao amanhã, e sinta a vocação de grandeza do Brasil" (M). Ou seja, o amanhã nesse discurso corresponde ao paraíso do discurso religioso. Em ambos, é preciso pagar com sacrifício e sofrimento um benefício longíquo que exige um ato de fé. Por isso mesmo, aqueles que crêem no governo são os bons brasileiros e merecem o futuro grandioso que o sujeito do discurso lhes promete e que POVO 2 está construindo. Aqueles que descrêem, "não são brasileiros" (F), são os "maus brasileiros" (F) que exigem para hoje o que está prometido para o "amanhã". Vale dizer: não têm paciência para esperar pelas promessas de um amanhã paradisíaco.

Esse discurso, produzido em lugar da palavra usurpada de POVO 2, reflete não o seu desejo, mas o simulacro de seu desejo, construído para substituir o desejo autêntico que é apagado.

Como é possível observar, as duas configurações de povo realizam dicotomicamente as propriedades do cidadão que, significativamente, foi apagado desse discurso: POVO 1 aponta para aqueles que têm direitos e POVO 2 corresponde àquela parcela de brasileiros que de seus direitos guardaram apenas o de cumprir com seus deveres. 
É através da análise dessa rede de representações que, pouco a pouco, é possível vislumbrar a dimensão do outro quando representado por povo no jogo enunciativo do discurso presidencial.

Nesse passo, seria igualmente possível estabelecer uma comparação entre POVO 2 e o psicótico. Da mesma forma que este último é despossuído de sua voz, POVO 2 também o é ao ser falado pela voz do mediador que simula ser seu porta-voz. Ou seja, o sujeito do discurso apieda-se dele, pede-lhe sacrifício e trabalho, mas opina e decide por ele, deixando-o permanentemente amordaçado.

Desse modo, POVO 2 representa uma armadilha discursiva definitiva para o segmento mais numeroso da população, pois esta configuração representa, de fato, a maioria silenciosa do povo brasileiro que se sacrifica enquanto espera por um amanhã paradisíaco com que lhe acena o sujeito do discurso.

Assim, os constantes deslocamentos da instância referencial (e a representação de povo) para a instância enunciativa ( imaginário do sujeito) possibilitaram a análise do funcionamento do sujeito do discurso presidencial e a descrição de duas das funções enunciativas que ele assume na enunciação desse discurso e que se instituem como propriedades fundamentais que caracterizam a natureza da interlocução que aí se instaura.

\section{POVO E SEUS EFEITOS DE SENTIDO}

Como é possível perceber, com base nas análises precedentes, povo possui um espectro referencial muito amplo, resultando daí um grau de ambiguidade bastante elevado, que converte este item lexical em um instrumento político muito eficaz. Através dele mobilizam-se o apoio, a colaboração, a força de trabalho, o sacrifício de um outro aparentemente genérico mas que, de fato, possui especificidade variada. Dessa forma, o item lexical povo, multifacetado semanticamente, desempenha papel essencial no jogo enunciativo desse discurso. Através dele, constrói-se a ilusão de um discurso cujo sujeito leva em conta a interlocução política, seja assumindo a função de porta-voz de POVO 1 ou de mediador de POVO 2.

$E$ igualmente graças a sua ambigüidade que o sujeito do discurso afirma que o Movimento de Março "tem raízes no povo" (CB), que as ações restritivas são praticadas "no interesse da Nação, do povo e da. Revolução" (CS) e que a Revolução se fez "em nome do povo e em seu favor" (CB). 
Sabe-se que essa noção de soberania do povo, invocada pelo sujeito desse discurso, emerge com a Revolução Francesa e torna-se obrigatória em um discurso que se pretende democrático. No jogo enunciativo do discurso em análise, ao se empregar POVO 1 e POVO 2, instaura-se o efeito metafórico de coletivo (INDURSKY, 1995). Desse modo, a representação do outro como povo resulta na construção de um simulacro de imagem democrática de seu sujeito, o que encobre a relação de dominação que subjaz a ele. Dito em outras palavras: o sujeito desse discurso autoritário simula exercer o poder pelo povo e para o povo. Ou seja, a ambigüidade desse item lexical tece o campo político: a interpelação do outro enquanto povo mobiliza seu sentido historicamente cristalizado e assim o sujeito do discurso instaura a ilusão de um discurso democrático pela tomada da palavra que, ao fazer-se em nome do povo, reveste-se do efeito de legitimidade.

O jogo ilusório proporcionado pela ambigüidade desse item lexical ainda pode ser examinado quando dois desses níveis referenciais apresentamse reunidos em uma mesma seqüência, tal como ocorre na seqüência discursiva que segue.

CB3 - [ a Revolução ] . . . representa o povo(1) e em seu nome exerce o Poder Constituinte de que o povo(3) é o único titular. (CB2 27.10.65 - Pal. Planalto - AI-2, p. 34)

Nesse recorte encontramos inicialmente POVO 1, que foi às ruas manifestar-se contra o Governo Goulart e apoiou posteriormente o golpe militar que assumiu o poder. Portanto, é claro que o Poder Constituinte, sendo exercido em "seu nome", implica uma relação de correferência, ou seja, o Poder Constituinte é exercido em nome de POVO 1. No entanto, a segunda ocorrência de povo vem marcada pelo sentido coletivo de povo, assinalado na grade referencial como POVO 3. Vale dizer: o povo, pelo sitema representativo, através de eleições, é o "único titular"do Poder Constituinte. Desse modo, a dupla ocorrência de povo nessa sequiência tece a trama discursiva que caracteriza esse discurso.

A repetição lexical, entendida como um dos modos de prover a coesão textual, de fato, oculta um processo de referenciação bastante complexo, já que remete para dois níveis referenciais diversos de um mesmo item lexical. Ou seja: a segunda ocorrência de povo indica retomada do mesmo item lexical, mas não garante sua retomada no mesmo nível referencial.

É preciso reavaliar a correferenciação, pois não só ela não se transfere automaticamente ao discurso, mas ainda pode ser mais uma fonte de ambigüidade na encunciação do discursivo. 


\section{ÚLTIMAS PALAVRAS}

Faz-se necessário, para encerrar, relacionar a forma de representação do outro através do item lexical povo, tão frequente nesse discurso, com a forma de representação através do item lexical cidadão, praticamente inexistente nesse espaço discursivo. Observe-se que, enquanto cidadão, por ser dotado de um conteúdo historicamente cristalizado, ao remeter para direitos e deveres, passou a representar efeitos de sentido indesejáveis, tornando seu uso incômodo e, por conseguinte, pouco freqüente nesse corpus, pela mesma razão e de forma diretamente proporcional, povo constituiu-se em um verdadeiro instrumento político, pois seu sentido historicamente construído vem ao encontro do jogo ilusório que a enunciação desse discurso produz.

As análises precedentes identificam uma rede sutil de efeitos de sentido que permitem vislumbrar a dimensão dicotômica do outro instaurada pelo viés de sua representação através do item lexical povo.

Assim, ao distinguirmos POVO 1 de POVO 2, distinguimos aqueles que são detentores de uma vontade veiculada por seu porta-voz, daqueles cujos direitos e necessidades são silenciados e substituídos por um simulacro que veicula, de fato, os interesses do mediador. Ou seja, POVO 1 aponta para aqueles que têm direitos e POVO 2 corresponde àquela parcela de brasileiros que de seus direitos guardaram apenas o de cumprir com seus deveres.

Assim sendo, cidadão foi discursivamente apagado nesse espaço discursivo e substituído por povo, que passou a ser expressivamente empregado como forma de representação do outro, em função dos efeitos de sentido de legitimidade e de unanimidade capazes de ocultar a dicotomia que lhe é inerente.

É preciso ainda ressaltar, nessas palavras conclusivas, que as duas funções enunciativas do sujeito do discurso presidencial, examinadas ao longo desse trabalho, são reveladoras do baixo grau de reversibilidade de que esse discurso é dotado, o que sinaliza de modo inequívoco a natureza autoritária desse discurso que não hesita em silenciar o discurso-outro no mesmo movimento que simula sua representação, caracterizando, assim, de forma muito peculiar, o modo como essas duas funções entretecem a monofonia (ORLANDI, 1989:44) sob a aparência da interlocução discursiva.

\section{NOTAS}

1 Ass sequiências discursivas de referência (SDR), componentes dos dois recortes discursivos que serão objeto de análise, estão numeradas con- 
secutivamente e em continuidade de um recorte para o outro. Os domínios discursivos de onde provêm as SDR estão identificados pela sigla que precede o número da referida SDR. Assim CB remete para Castello Branco; CS, para Costa e Silva; M, para Médici; G, para Geisel e F, para Figueiredo. Por fim, após a SDR, entre parênteses, ocorre a retomada da sigla identificadora do domínio, seguida de um número que remete para a fonte bibliográfica, ao final do trabalho.

\section{REFERÊNCIAS BIBLIOGRÁFICAS}

AUTHIER, Jacqueline. Hétérogénéité montrée et hététogénéité constitutive: éléments pour une approche de l'autre dans le discours. DRLAV, Paris, n. 26, pp. 91-151, 1982.

FIORIN, José Luiz. O regime de 64: discurso e ideologia. São Paulo: Atual, 1988.

INDURSKY, Freda. A fala dos quartéis e as outras vozes: uma análise do discurso presidencial da Terceira República Brasileira. (1964-1984). Campinas: IEL/UNICAMP, 1992 (Tese de doutorado).

, A construção metafórica do povo brasileiro. Organon, Porto Alegre, n. 22, 1995 ( No prelo).

ORLANDI, Eni. A linguagem e seu funcionamento: as formas do discurso. São Paulo: Brasiliense, 1983.

1984.

, Segmentar ou recortar? Série Estudos, Uberaba, n. 10, pp. 9-26,

, Silêncio e implícito: produzindo a monofonia. In GUIMARÃES, Eduardo (org). História e sentido na linguagem. Campinas: Pontes, 1989.

, As formas do silêncio: movimento dos sentidos. Campinas: Ed. da Unicamp, 1992.

, (org.) Discurso fundador: a formação do país e a construção da identidade nacional. Campinas: Pontes, 1993.

OSAKABE, Haquira. Argumentação e discurso político. São Paulo: Kairós, 1979.

PÊCHEUX, Michel. Les vérités de la Palice. Paris, Maspéro, 1975. Trad. bras.: Semântica e discurso. Campinas, Ed. da Unicamp, 1988.

ZOPPI-FONTANA, Monica G. Modernização e discuros democráticos: porta-vozes esclarecidos nos tempos da transição. Campinas: IEL/UNICAMP, 1994 (Tese de doutorado). 


\section{DISCURSOS PRESIDENCIAIS}

CB1 - CASTELLO BRANCO, Humberto de Alencar. Discursos. Brasília: Secretaria da Imprensa, 1964.

$\mathrm{CB} 2-$ . Brasília: Secretaria da Imprensa, 1965.

CB3 . Brasília: Secretaria da Imprensa, 1967.

CS1 - COSTA E SILVA, Arthur da. Pronunciamentos do Presidente. Brasília: Secretaria de Imprensa e de Divulgação da Presidência da República, s. d. v. 1.

CS2 . v. 2.

M - MÉDICI, Emílio Garrastazu. Nova consciência de Brasil. Brasília: Secretaria de Imprensa da Presidência da República, 1970.

G1 - GEISEL, Ernesto. Discursos: 1974. Brasília: Assessoria de Imprensa e Relações Públicas daPresidência da República, 1975. v. 1.

G2 . Discursos: 1975. Brasília: Assessoria de Imprensa e Relações Públicas da Presidência da República, 1976. v. 2.

F1 - FIGUEIREDO, João. Discursos: 1979. Brasília: Secretaria de Imprensa e Divulgação da Presidência da República, 1981. v. 1.

F2 - _ Discursos: 1980. Brasília, Secretaria de Imprensa e Divulgação da Presidência da República, 1981. v. 2. 